\title{
Análisis crítico de la prueba material en delitos de porta- ción ilegal de armas de fuego
}

\section{Evaluation of the judge or Court in Material Evidence of firearm}

\author{
Julio Roberto Herrera González \\ Universidad de San Carlos de Guatemala. \\ jrobherrera@hotmail.com
}

Recibido: $16 / 07 / 2021$

Aceptado: 16/08/2021

\section{Referencia del artículo}

Herrera González, J. R. (2021). Análisis crítico de la prueba material en delitos de portación ilegal de armas de fuego. Revista Diversidad Científica, 1(1). 117-128.

DOI: https://doi.org/10.36314/diversidad.v1i1.13

\section{Resumen}

Que significa prueba, su origen, de la pretensión de convencer al juez de darle credibilidad a la plataforma fáctica. Además de tomar en consideración aspectos relevantes sobre el estudio de la Prueba, es decir los diferentes sistemas que pueden utilizar los aplicadores de Justicia para valorar la prueba, se realizó un análisis, de aspectos importantes de dicha aplicación, cuestionando si son ignorados o desechados, por dichos jueces al momento de dictar sentencia, su justificación, de su idoneidad, de los aspectos tomados en cuenta de los diferentes sistemas de valoración de prueba. De las sentencias condenatorias emitidas, valorando la prueba material en nuestro caso el arma de fuego, por el delito de portación llegal de armas de fuego de uso civil y/o deportivas.

Palabras clave: prueba, valoración, sentencia, sistema 


\begin{abstract}
What does evidence mean, its origin, its purpose, whose intention is to convince the judge to give credibility to the fascic platform, In addition to taking into account relevant aspects about the study of the Evidence, that is, the different systems that the applicants of Justice can use To assess the evidence, an analysis was carried out of important aspects of said application, questioning whether they were ignored or rejected by said judges at the time of sentencing, and if even so, they justify whether said application was the most suitable, and that If they took into consideration all the aspects of the different systems of evaluation of evidence, the aim of the present research work is to demonstrate through constructive criticism, which is what the Judges or Courts currently take into consideration to issue convictions, for the crime of illegal possession of a firearm for civil and / or sporting use, when they value a firearm.
\end{abstract}

Keywords: test, assessment, sentence 


\section{Introducción}

La investigación nos da un panorama, que abarca la teoría general de la prueba, principios fundamentales relacionados, sistemas de valoración, y la utilidad que todos estos aspectos proveen y que le permite a los jueces y magistrados, poder determinar con mayor precisión la sentencia más acertada, principalmente cuando dicha sentencia es condenatoria, y que la misma sea apegada a derecho, se hace un análisis del uso de estas herramientas verificando si efectivamente fueron bien utilizadas o fueron ignoradas por el aplicador de justicia, utilizando una serie de cuestionamientos respecto al argumento o razonamiento emitido en la sentencia, $y$ es ese el preciso momento que nos permite poder tener una mejor capacidad de análisis, en cuanto a la apreciación de la prueba, principalmente la prueba material, que a nuestro criterio, es uno de los tipos de prueba más importante, siendo que es considerable admitir otros medios de prueba, sin embargo, en nuestra investigación nos referimos principalmente a la prueba material aportada, exclusivamente en el delito de Portación llegal de Armas de Fuego de Uso civil y/o deportivas que va aunada paralelamente con el examen exhaustivo de informes periciales, siendo estos balísticos, dactiloscópicos, análisis de la Dirección General de Armas y Municiones DIGECAM. Del Ejército de Guatemala, croquis del lugar de los hechos, croquis de la movilidad del supuesto sindicado, en el momento en que ocurrieron los hechos, no menospreciando el arma que se supone le fue incautada al sindicado, cuando fue aprehendido, se han considerado los diferentes tipos de prueba y por qué son determinantes según los sistemas de valoración de la prueba para dictar sentencia, y la determinación que exigen los sistemas de valoración de la prueba ha tomado el juez para dictar sentencia condenatoria. Es sumamente importante hacer alusión a la valoración de la prueba en cuanto a tiempo, modo y lugar, en que sucedieron los hechos, además cabe agregar a ello, la declaración testimonial, que permita verificar cuán importante son estas pruebas, para la emisión de una sentencia de carácter condenatorio. La relevancia de aspectos trascendentales, de valor probatorio se conjuga con elementos esenciales como lo son la contundencia de la prueba, la individualización de la misma, que definitivamente son herramientas para la valoración de la misma, en este caso el arma de fuego.

\section{Contenido}

El concepto "delito" se ha ido desarrollando a través de los tiempos, los autores se han basado en diferentes ideas políticas, filosóficas y culturales para definirlo, existiendo así una variedad de corrientes que han explicado esta parte de la ciencia del derecho penal conocida como Teoría del Delito para aplicar la ley según corresponde en cada caso concreto. 
Los alemanes empezaron a construir un concepto jurídico del delito y le denominan teoría general del delito. Existe un sinfín de perspectivas de esta parte del derecho penal, pero en general buscan determinar frente a una conducta si la misma puede ser delictiva o no, visualizando una posible sentencia (Zaffaroni, 2012: 24).

\section{Definiciones Generales}

Para entender la esencia y naturaleza de la teoría del delito es preciso definir algunos conceptos fundamentales:

\subsection{Sistema de valoracion de prueba}

Para un mejor entendimiento del tema considero que es necesario entender lo que es la definición, referente a la valoración de la prueba, es decir, lo que debe entenderse sobre lo que es la prueba, de su aplicación en nuestro medio, de que herramientas se auxilia, además de algunos otros conocimientos que servirán de soporte para un mejor aprovechamiento.

\subsection{La prueba Material Penal}

Nos remontamos a la antigüedad, y al abordar el término prueba, éste se empezó a utilizar en el antiguo Imperio romano, dicha acepción deriva del latín probatio, probationis, que a su vez procede del vocablo probus, cuyo significado es bueno. De lo cual se infiere, que todo aquello que ofrece un resultado el cual fue debidamente probado, es bueno, que es parte una cosa que es real, y que puede probarse y es paralelo a una revisión, es lo que tiene su origen cuando una cosa es auténtica. Cualquier tipo de proceso debe tener un enfoque o actividad procesal donde obligadamente se debe haber practicado un tipo de actividad probatoria, debemos apuntar al término como una especie de principio y/o referencia de actuación, que sea apegado a la realidad. Sobre esta base entonces, nos preguntamos cuales son las características esenciales para definir el concepto de prueba: A- elemento objetivo: todo aspecto que se utilice para que el juzgador conozca los hechos. De tal manera que debe de tomar en cuenta todos aquellos aspectos que pretenden descubrir y obtener el origen de la prueba, y que esté íntimamente 
ligada a la práctica. B- elemento subjetivo: Grado de convencimiento que resulta en la visión o criterio del juez.

\section{Valoración de la prueba}

Es importante resaltar la plataforma fáctica, en la cual se funda el ente investigador, cuya pretensión es ser demostrada y de esa cuenta convencer al juez o Tribunal, para que aplique el fundamento legal que corresponde y así dar solución a la pretensión que sostienen.

La importación de la prueba y de que la se encuentre respaldada de la respectiva plataforma probatoria, y que se demuestra con que efectivamente sucedió el hecho señalado, es lo que verifica y comprueba su veracidad, el autor Bentam 2003 pag. 14 señala que el arte del proceso no es, esencialmente otra cosa que el arte de administrar la prueba.

Según el autor Eduardo Alejos Toribio en su libro "Sistemas de Valoración de la Prueba Penal" estudia los sistemas de valoración de la prueba de la forma siguiente: Sistema de la prueba legal o tasada y Sistema de la libre valoración de la prueba, este a su vez se subdivide en: Sistema de la libre convicción y sistema de la sana crítica razonada.

\subsection{Sistema de la prueba legal o tasada}

También conocido como sistema de la prueba legal o formal. En Guatemala el sistema de prueba legal o tasada quedó en desuso con la vigencia del Código Procesal Penal Decreto 51-92 del Congreso de la República. Es un sistema de excesiva rigidez donde la ley le indica al juzgador el valor exacto que debe darle a los medios de prueba. En este sistema la ley procesal explica bajo qué condiciones el juez debe condenar y bajo cuales debe absolver, independientemente de su propio criterio. El juez examina la prueba según esquemas abstractos y apriorísticos consagrados en la ley, sin atender a elementos concretos o modalidades especiales, que inciden en la credibilidad del medio. El Código Procesal Penal anterior, se basaba en este sistema. Por ejemplo, en el artículo 701 estipulaba que la confesión lisa y llana, con las formalidades de ley, hacía plena prueba, el artículo 705 preceptuaba que no hacía prueba en adulterio la confesión de uno solo de los encausados. 
Ese sistema se basa en la desconfianza hacia los jueces y pretende limitar su criterio interpretativo.

Este sistema de prueba legal o tasada representa, sin duda alguna, una intromisión indebida del legislador en un ámbito que solo corresponde a quién aprecia directa y personalmente los elementos de prueba, y actúa en el procedimiento en el ejercicio del poder jurisdiccional. Es por ello que hoy en día, se encuentra en desuso aunque sus reglas no deben ser descuidadas a la hora de la libre valoración del Juez.

\subsection{Libre convicción}

En este sistema el Juez toma su decisión sin tener que basarse en reglas abstractas y generales de valoración probatoria, sino que en base a la prueba presentada debe decidir cuál es la hipótesis que estima como cierta. A diferencia del sistema de sana crítica razonada no se exige la motivación de la decisión.

En nuestro sistema legal, en la formación de la convicción de los Jueces del Tribunal de Sentencia, intervienen las pruebas y las presunciones, las primeras son medios o instrumentos de verificación directa o indirecta de los hechos ocurridos y las presunciones permiten acreditar la convicción o certeza a través de supuestos de certidumbre o consideraciones lógicas derivadas de los medios de prueba.

\subsection{Sana Critica Razonada}

La sana crítica es la unión de la lógica y la experiencia, sin excesivas abstracciones de orden intelectual, pero también sin olvidar esos preceptos que los filosóficos y los psicólogos, tendientes a asegurar el más certero y eficaz razonamiento. Por imperativo legal el tribunal de sentencia debe apreciar la prueba según las reglas de la sana crítica razonada y resolver por mayoría de votos. Podemos definir las reglas de la sana crítica razonada como reglas del correcto entendimiento humano, contingentes y variables con relación a la experiencia del tiempo y el lugar, pero estables y permanentes en cuanto a los principios lógicos en que debe apoyarse la sentencia. Es decir el juez debe tomar en cuenta no solo los principios de la lógica, sino también los de la experiencia, determinados por razones de tiempo y lugar.

Este sistema, aunque no establece ninguna regla para apreciar las pruebas, hace referencia a un procedimiento complejo de toma de decisiones, el Juez es libre de 
convencerse según su íntimo parecer, pero existen límites bien establecidos, como la obligación de fundamentar la decisión que impide arbitrariedad e improvisación, la fundamentación que no puede hacerse con base a medios de prueba obtenidos ilegalmente, o la prohibición expresa de valorar el silencio del sindicado o la no declaración del mismo, el cual no puede utilizarse para concluir en la existencia o inexistencia de un hecho perjudicial.

Es decir que para valorar la prueba de conformidad con el sistema de la sana crítica razonada, los jueces deben considerar los conocimientos aportados por peritos, las leyes de la lógica, los principios psicológicos, el sentido común, así como las experiencias que la vida cotidiana ha aportado a cada uno; evidentemente, la elaboración de una decisión no es tarea fácil, pues se trata de solucionar en forma definitiva el conflicto planteado, los jueces de sentencia están investidos para tomar la decisión, debiendo responder únicamente a la cuestión controversial planteada por la acusación y apoyados únicamente en la prueba incorporada. La sana crítica razonada exige fundamentación o motivación de la decisión, la expresión de los motivos por los que se decide de determinada manera y la mención de los elementos de prueba que se tuvieron en cuenta para arribar a una decisión y su valoración crítica. (Angélica Amparo Godoy Estupe "Análisis Jurídico de la Valoración de la Prueba en el Proceso Penal Guatemalteco”. Guatemala, Junio de 2006.).

\subsection{Sistema de valoracion de la prueba}

Un sistema probatorio es aquel estatuto que regula la forma de indagación en los hechos dentro del proceso, que se manifiesta en las formas y medios a través de los cuales se puede arribar a una verdad de los hechos, y en el modo de valorar esos medios. Este sistema nos permite saber cómo el magistrado deberá formar su convencimiento respecto a los hechos.

Cabe señalar que éstos se han ajustado a diversos modelos procesales, como se da en el caso de la prueba legal o tasada (sistema inquisitivo); íntima convicción (acusatorio) y la libre valoración o sana crítica. Su proceso de operatividad se vino dando a raíz de los criterios adoptados o desechados de acuerdo al tiempo en que la discusión se suscitaba y, particularmente, atendiendo al grado de desarrollo de la sociedad, a la conformación del sistema de persecución penal y al modelo de política criminal del Estado (criterio de temporalidad y de ubicuidad).

Pues bien, antes de desarrollar los diversos sistemas de valoración probatoria, es indispensable prima facie recordar que en situaciones conflictivas se utilizó como 
herramienta la opinión de un tercero, pues, si los contendientes eran incapaces de resolver conflictos por ellos mismos, recurrían hacia la opinión de este último, donde simple y llanamente la respetaban.

Así las cosas, a falta de cualquier norma escrita u oral se dejaban guiar por la razón del tercero elegido de no tener otras opciones. Así pues, como consecuencia de aquello, se puede argüir que el primer sistema fue el de valoración libre.

\subsection{La prueba legal o tasada}

En este sistema la labor del legislador se enfocaba en la idea de que los jueces debían tener una limitación frente a lo que pensaran o sintieran. Visto así, la confianza que el primero tenía por el segundo era escaso, pues se indicaba cuál era el peso específico de cada prueba, llevando al magistrado ante una limitación. Entonces, al estar las reglas de valoración establecidas en las leyes, se indicaba al juez cuándo y en qué medida debía considerar un enunciado fáctico como probado, motivo por el cual es que se podría decir que se estaba ante un sistema de numerus clausus.

En este sistema, existía una distinción entre la prueba legal positiva con una negativa: (a) en la primera, la Ley establecía que el juez debe dar por probada la hipótesis acusatoria, aunque ello contravenga su convicción, generando una obligación para condenar o absolver; mientras que (b) en la segunda, la Ley prescribía que el juez no debe considerar como probada la hipótesis acusatoria, pese a que también vaya en contra de su convicción, obligando una absolución.

\subsection{Criterio de íntima convicción}

Si bien es cierto, el origen de este sistema se halla en la Revolución francesa, ya que en esta época se encontraba vinculado a la institución del jurado popular; sin embargo, se podría afirmar que no fue así, puesto que en Francia, con anterioridad ya se habían establecido preceptos legales que la establecían, como es el caso de la Ordonnance de Moulins: donde durante veintiocho meses, la reina Catalina de Médicis recorría Francia para mostrarle al Rey que su pueblo se había olvidado de la disidencia o discrepancia religiosa, teniendo como objetivo establecer decretos de paz, cuya fecha final fue el 1 de mayo de 1566 en la ciudad de Moulins. 
La ventaja de este sistema, sobre el de prueba legal o tasada es que la convicción del magistrado, no estaba atado a formalidades preestablecidas, que podían obstaculizar la obtención de la verdad; sin embargo, este entender de la íntima convicción dio, también, lugar a la creación de una concepción extrema-subjetivista, dado que existía ausencia de reglas.

El juez era libre de convencerse, según su saber y entender, razón por la cual es que se presentaba una suerte de imperfección al no exigirse el deber de motivación del fallo, pudiendo ser propenso a la arbitrariedad y, por ende, conllevar a una injusticia.

\subsection{Libre valoración o sana crítica}

Basada en la retórica de Aristóteles, en su momento, Devis Echandía apuntó que en la Grecia antigua se encontraban los antecedentes de este sistema de valoración probatoria, pues se solía hacer mención de una crítica con carácter lógico y, por ende, razonada; propiciando una especie de lógica, ajena a perjuicios de orden religioso y a fanatismos de otra índole.

De lo expuesto, se puede inferir que el citado autor haya tenido en cuenta que en la Grecia antigua se aplicaba el entinema, aquel silogismo utilizado para identificar a lo evidente o lo sobreentendido, muchas veces, hoy en día, confundido con la lógica o las máximas de la experiencia, por cierto.

Es más, resuena la postura de que la libre valoración o la sana crítica surgió en España, donde se disponía que las personas designadas como testigos debían ser examinados y calificados por parte del Consejo Real conforme a las reglas de la sana crítica (ver art. 148 del Reglamento sobre el modo de proceder el Consejo Real en los negocios contenciosos de la Administración de 1846).

La práctica de este sistema faculta al juez, la libertad de poder valorar las pruebas de acuerdo con su lógica y a las máximas de la experiencia, gracias a que el juzgador no está obligado a seguir, exclusivamente, reglas positivisadas que lo restringían más allá de lo convencional como se daba en la prueba legal.

En el sistema de libre valoración o sana crítica, se tiene que determinar el valor probatorio de cada medio de prueba a través de una valoración libre, según el caso en 
concreto; pues, este sistema se dirige al juez para que éste descubra la verdad de los hechos derivados del proceso, solamente, basándose en un apoyo racional y cognitivo que ofrecen los medios de pruebas que se encuentran al alcance.

El sistema en referencia, no determina la manera específica en que el juez ha de ejercer al momento de aplicar la valoración libre y prudencialmente; no obstante, el magistrado debe seguir una suerte de percepción íntima e instantánea. Como es de saber, el juez se va encontrar envuelto, de una u otra manera, en su íntima convicción o en sus creencias, cuando tenga que determinar un valor probatorio, a fin de llegar a conseguir una especie de certeza sobre los hechos que se han suscitado en el proceso.

\section{Conclusión}

La pretensión del presente trabajo de investigación, fue desarrollar de manera teórica la importancia en el proceso penal de la valoración de los medios de prueba para emitir una sentencias condenatoria o absolutoria de manera fundada.

En los delitos portación llegal de arma de fuego de uso civil y/o deportivo, no es suficiente que se pueda condenar a las personas únicamente con la prueba material que es el arma de fuego, ya que toda sentencia debe de dictarse de manera razonada, motivada, que expresen los motivos de hecho y derechos que arribaron a una conclusión que confiera certeza y no de lugar a dudas, ya que la valoración de la prueba es la columna vertebral del sistema procesal penal, este debe de evolucionar porque su forma de valorar la prueba ya que esto es un parámetro para poder constatar el avance o desarrollo democrático en la sociedad.

\section{Declaración}

El estudio se realizó de acuerdo al Código de Ética y Buenas Prácticas COPE.

\section{Conflicto de intereses}

El autor declara no tener ningún conflicto de intereses. 


\section{Referencias}

Barrientos Pellecer, Cesar Ricardo. Derecho procesal penal guatemalteco $1^{\text {a }}$. ed.; Ed. Magna Terra Editores. Guatemala. 1995

Carnelitti, Francesco. Derecho procesal civil y penal. Tomo III. Biblioteca Milán, Italia, 1992.

Chiovenda, Giuseppe. Oralidad y la prueba. Ensayos. II 1931.

Coutre, Eduardo. Estudios de derecho procesal civil. Tomo II. Ed. EDIAR, Buenos Aires, Argentina

Devis Echandia ,Hernando. Teoría general de la prueba judicial. Tomo I. Ed. Savalia, Buenos Aires, Argentina

Fabrega P. Jorge. Teoría general de la prueba. Ediciones Jurídicas. Gustavo Ibáñez. Bogotá Colombia, 1997.

Florian, Eugenio. De las pruebas penales. Tomo I y Tomo II. Ed. Temis. Bogotá, Colombia. 1998.

Instituo de la Defensa Pública Penal. Valoración de la Prueba. Guatemala.

Perez Ruiz, Yolanda. Valoración de la prueba. Fundación Mirna Mack. Guatemala, 2001.

Zafaroni, E.R. 2012 L CuestiónCriminal, Buenos Aires Argentina. 


\section{Sobre el autor \\ Julio Roberto Herrera González}

Licenciado en Ciencias Jurídicas y Sociales, Abogado y Notario, egresado de la Universidad Panamericana de Guatemala, con Pensum cerrado de Maestría en Derecho Civil y Procesal Civil.

\section{Copyright (c) Julio Roberto Herrera González}

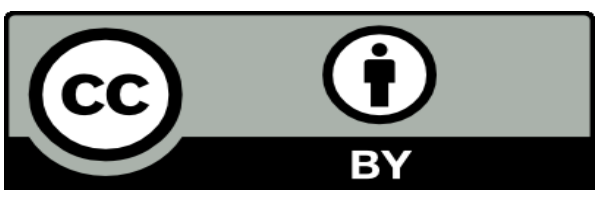

Este texto está protegido por una licencia CreativeCommons 4.0.

Usted es libre para compartir, copiar y redistribuir el material en cualquier medio o formato y adaptar el documento, remezclar, transformar y crear a partir del material para cualquier propósito, incluso comercialmente, siempre que cumpla la condición de atribución: usted debe reconocer el crédito de una obra de manera adecuada, proporcionar un enlace a la licencia, e indicar si se han realizado cambios. Puede hacerlo en cualquier forma razonable, pero no de forma tal que sugiera que tiene el apoyo del licenciante o lo recibe por el uso que hace. 